\title{
E.M. SODANO
}

\section{REFERENCES}

[ 1 1 E.M. SODANO: "General Non-Iterative solution of the Inverse and Direct Geodetic Problems ", Bulletin Géodésjque, 1965, $\mathrm{N}^{\circ} 75$, pp. 69-89.

[2]*E.M. SODANo: " A Rigorous Non-Iterative procedure for Rapid Inverse Solution of Very Long Geodesics", Bulletin Géodésique, 1958, $n^{\circ} 47 / 48$, pp. 13-25.

* Errata sheets, not previously published, are attached.

\section{ERRATA SHEETS}

"General Non-Iterative Solution of the Inverse and Direct Geodetic Problems " by E.M. SodAno, Bulletin Géodésique, 1965, $N^{\circ} 75$, pp. 69-89.

Page 69: first word of line before last of paragraph I should be "beyond".

Page $70:$ in third line from end of paragraph III, a decimal point should be before the 5 instead of the period after previous word.

Page 70 : in line 7 of paragraph IV, the word should be "parameter" instead of its plural.

Page 75 : in third line of Appendjx B, place comma before $S$.

Page 76 : in heading of lower table, the correct spelijng js "and".

Page 89 : in third line of Appendix G, the word should be "indication" instead of its plural.

" A Rigorous Non-Iterative Procedure for Rapid Inverse solution of Very Long Geodesics " by E.M. SoDANo, Bulletín Géodésique, $1958, \mathrm{~N}^{\bullet} 47 / 48$, pp. 13-25.

Page 21 : at end of tenth line from end of page, place "cotangent" in front of $\alpha_{1-2}$ and in front of $\alpha_{2-1}$. 